\title{
Co-delivery of paclitaxel and curcumin to foliate positive cancer cells using Pluronic-coated iron oxide nanoparticles
}

\author{
Chinmay G. Hiremath ${ }^{1} \cdot$ Geetha B. Heggnnavar ${ }^{2} \cdot$ Mahadevappa Y. Kariduraganavar $^{2} \cdot$ Murigendra B. Hiremath $^{1}$
}

Received: 18 March 2019 / Accepted: 6 June 2019 / Published online: 13 June 2019

(c) The Author(s) 2019

\begin{abstract}
Active targeting of folic acid and passive targeting of magnetic nanoparticles to bring about co-delivery of hydrophobic chemotherapeutic agents were the focus of this work. Co-precipitation in alkaline environment was employed for synthesizing $\mathrm{Fe}_{3} \mathrm{O}_{4}$ nanoparticles and stabilized by oleic acid. Aqueous dispersibility of oleic acid coated nanoparticles was brought about by folic acid modified Pluronic F127 and Pluronic F127 mixture. Folic acid is used as a targeting agent which was joined to Pluronic F127 via diethylene glycol bis(3-aminopropyl) ether spacer. The nanocomposite was used to delivery hydrophobic anticancer drugs, paclitaxel, and curcumin. Successful modification at each step was confirmed by FTIR and NMR. Quantitative analysis of attached folic acid indicated a total of $84.34 \%$ amount of conjugation. Nanoparticles characterization revealed the hydrodynamic size of and nanocomposite to be $94.2 \mathrm{~nm}$ nanometres. Furthermore, transmission electron micrograph reveals the size of the nanoparticle to be $12.5 \mathrm{~nm}$ hence also shows the superparamagnetic activity. Drug encapsulation efficiency of $34.7 \%$ and $59.5 \%$ was noted for paclitaxel and curcumin, respectively. Cytotoxic property of drug-loaded nanocomposites was increased in case of folic acid functionalized nanoparticles and further increased in the presence of an external magnetic field. Cellular uptake increased in the folic acid conjugated sample. Further many folds in the presence of an external magnetic field.
\end{abstract}

Electronic supplementary material The online version of this article (https://doi.org/10.1007/s40204-019-0118-5) contains supplementary material, which is available to authorized users.

Murigendra B. Hiremath

murigendra@kud.ac.in; murigendra@gmail.com

1 Department of Biotechnology and Microbiology, Karnatak

University, Pavate Nagar, Dharwad, Karnataka 580003, India

2 Department of Chemistry, Karnatak University, Dharwad, Karnataka 580003, India 


\section{Graphic abstract}

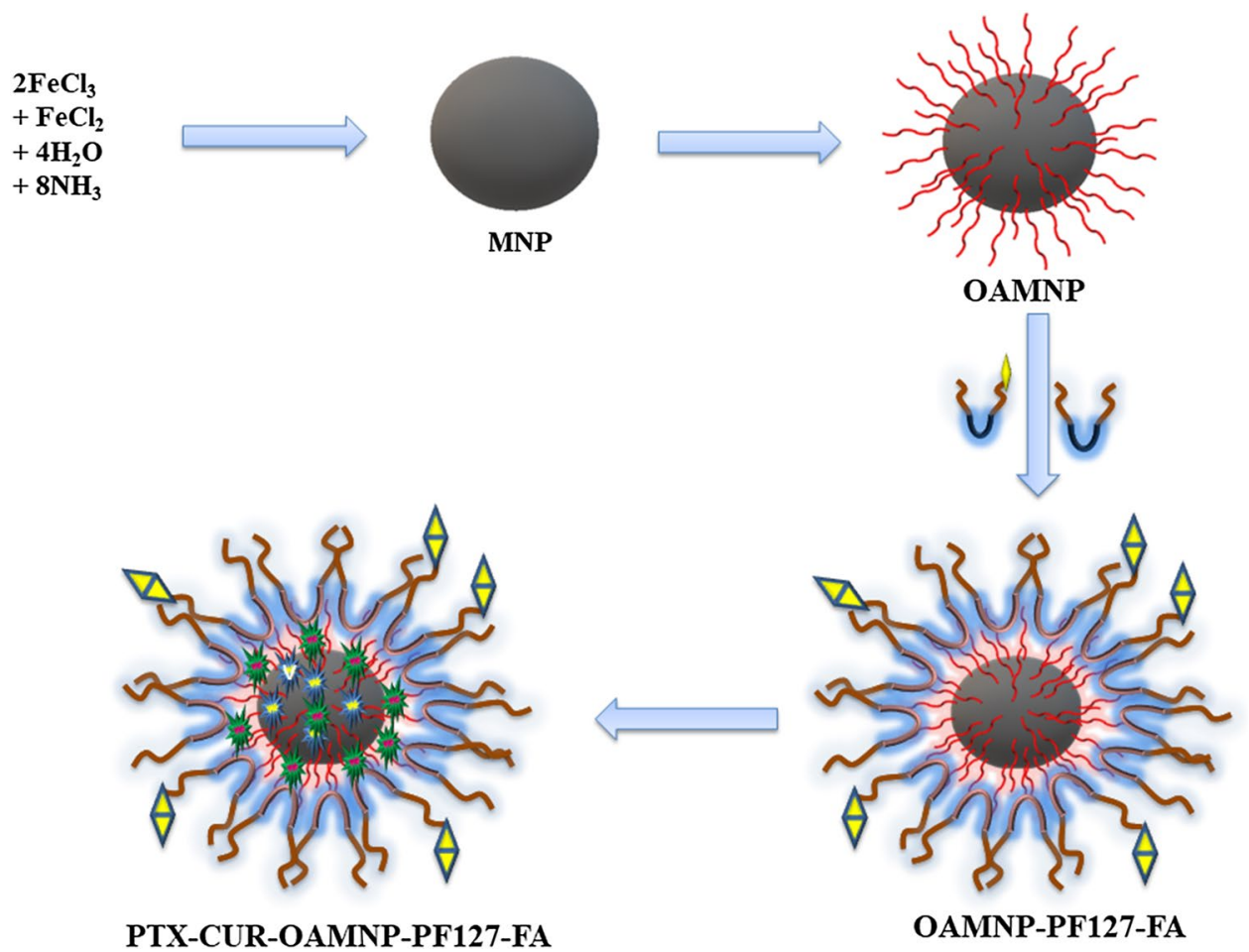

Keywords Pluronic $\cdot$ Magnetic nanoparticles $\cdot$ Folic acid $\cdot$ Curcumin $\cdot$ Paclitaxel

\section{Introduction}

Cancer is one of the world's highly distressing diseases, with 10 million new reports annually (Hamzehalipour Almaki et al. 2017). Chemotherapy drugs are effective in curbing cancer; however, drugs elicit toxicity. Toxicity is due to indiscriminate biodistribution thus drastically damaging patient's quality of life. Moreover, some of the potent cancer chemotherapeutic agents suffer from low aqueous solubility and poor bioavailability (Brigger et al. 2002; Khodabandehloo et al. 2016). Targeted drug delivery, a promising and growing technology in cancer therapy, involves delivery of chemotherapeutic molecules directly to the site of cancer thus ensuring restricted drug distribution, enhancement of efficacy and safety of drug (Chauhan and Jain 2013). One such technology gaining importance is nanotechnologybased targeted drug delivery, which allows encapsulating the chemotherapeutic agents and also brings about site-specific distribution with a help cancer-specific or a tumor abundant markers for targeting cancer (Veiseh et al. 2010; Lomis et al. 2016).

There are a wide range of nanoparticulate materials, such as liposomes, polymeric nanoparticles, solid lipid, dendrimers, etc. being developed for the delivery of therapeutic compounds (Mudshinge et al. 2011). $\mathrm{Fe}_{3} \mathrm{O}_{4}$, magnetite, and nanoparticles are finding wide-ranging use in biomedical application, as it can be localized to required site of action using exterior magnetic field(Yallapu et al. 2011). $\mathrm{Fe}_{3} \mathrm{O}_{4}$ nanoparticle bestows good biocompatibility and post metabolism is converted into iron salts which is eventually incorporated by the body (Gupta and Gupta 2005; Sun et al. 2008; Veiseh et al. 2010). Often, capping agents are used to stabilise the nanoparticles, and one such capping agent is oleic acid (OA). OA is a biomolecule and is pharmaceutically inert material (Jin et al. 2010).

Pluronic F127 (PF127) is an A-B-A-type triblock polymer consisting of poly(ethylene oxide)poly(propylene oxide)—poly(ethylene oxide) blocks, $\left(\mathrm{PEO}_{100}-\mathrm{PPO}_{65}-\mathrm{PEO}_{100}\right)$. Pluronics display a twin property in water, PEO displays solubility in aquatic environment, and the PPO shows no aqueous solubility (Wang et al. 2007; Lin et al. 2009). The exterior PEO wreath inhibits protein interaction and stealth's from immune recognition (Huang et al. 2009). Interior PPO block interacts hydrophobically with hydrophobic chemotherapeutic agents, i.e., it can encapsulate the drug molecule (Lin et al. 2009). Another advantage of PF127 is terminal hydroxyl groups which can be modified to desired functionality (Song et al. 2010). 
Folic acid (FA) is vitamin B9, an essential biomolecule for the one-carbon metabolic reactions, methylation, DNA biosynthesis, and repair, and thus, there is amplified expression of folic acid receptors (FRs) in the breast, ovarian, endometrial, and colon cancer (Sudimack and Lee 2000; Sun et al. 2006; Locasale 2013). Conversely, the expression of FRs in typical human tissues is limited to a low level (Kelemen 2006). FA and FA conjugates undergo receptor-mediated endocytosis upon binding to FRs, so the FA-modified drug-delivery systems deliver desired therapeutics to tumor cells (Zhao et al. 2008; Cheung et al. 2016). Thus, hypothesizing enhanced potency and reduced off-site toxicity foliatelinked therapeutic agents in contrast to non-targeted drugs (Xia and Low 2010).

Paclitaxel is a potent microtubule inhibitor extracted from Taxis brevifolia (ten Tije et al. 2003). This highly potent molecule, due to its greasy nature, is subjected to poor bioavailability (Zähres et al. 2006). Reports of paclitaxel treatment in breast cancer indicate the condition of myelotoxicity and neurotoxicity in patients (Zähres et al. 2006; Pace et al. 2007). Furthermore, paclitaxel treatment, like other chemotherapeutic agents, exhibits chemoresistance, one of the major challenge, in cancer therapy, owing to ATP binding cassettes (ABC) and $p$-glycoprotein (PGP) transporters (Koutras et al. 2008; Gottesman et al. 2002). Furthermore, evidence suggests the involvement of nuclear factor $\mathrm{\kappa B}$ (NF$\kappa \mathrm{B}$ ), which promotes cell proliferation and up-regulates metastasis genes (Sui et al. 2013). Despite high potency to cure cancer, paclitaxel finds limited clinical use due to poor bioavailability, systemic toxicity, and drug resistance.

Curcumin is a pharmaceutically safe pleiotropic drug isolated from root modifications of Curcuma longa (Shishodia et al. 2005; Kang et al. 2009). Along with its anticancer property, curcumin suppresses the nuclear factor $\mathrm{KB}$ (NF$\kappa \mathrm{B})$, a factor which up-regulates the proliferation and metastasis genes, thus curbs down chemoresistance induced by paclitaxel in breast cancer (Koutras et al. 2008; Hatcher et al. 2008; Kang et al. 2009). Furthermore, curcumin also downregulates the expression of major $\mathrm{ABC}$ transporters which are major pathways in multidrug resistance in taxanes (Kuttan et al. 1985; Huang et al. 1988; Ma and Mumper 2013; Tian et al. 2016). Thus, a number of researchers think it is advisable to co-deliver paclitaxel with curcumin, since the latter is reported to bring about chemosensitization of former (Longley and Johnston 2005; Ganta and Amiji 2009; Yallapu et al. 2012; Sui et al. 2013).

Present work aimsto develop OA-coated iron oxide nanoparticle stabilized by FA-modified PF127 (OAMNPPF127FA) for active and passive delivery of hydrophobic drugs, curcumin and paclitaxel, to breast cancer cells. Folic acid was attached to PF127 by amine homofunctionalized Diethylene glycol moiety. We hypothesize hydrophobic drugs partition between OA and PPO hydrophobic corona.
Furthermore, nanocomposites were considered to be thought externally localized and selectively target the foliate positive cell lines.

\section{Materials and methods}

\section{Materials}

Iron (III) chloride $\left(\mathrm{FeCl}_{3}\right)$ and iron (II) chloride tetrahydrate $\left(\mathrm{FeCl}_{2} 4 \mathrm{H}_{2} \mathrm{O}\right)$ as nanoparticle components, ammonium hydroxide (30-33\%M) for precipitation, Pluronic-F127, paclitaxel, folic acid, (1-ethyl-3-(3-dimethylaminopropyl) carbodiimide (EDC), and $N$-hydroxy succinamide (NHS) for crosslinking were procured from Sigma-Aldrich. Oleic acid, diethylene glycol bis (3-aminopropyl) ether, 1,1'-carbonyldiimidazole (CDI), and curcumin were purchased from TCI chemicals. 5-fluorouracil and dimethyl sulfoxide (DMSO) were purchased from MOLchem. Nitrogen purged Milli-Q was used in all the steps involved in the synthesis and formulation of magnetic nanoparticles.

\section{Synthesis of Pluronic $P$ 127-CDI adduct}

PF127-CDI adduct was synthesized as mentioned in publications (Fujita et al. 1999; Zhang et al. 2011). Purification of PF127 was brought about by dissolving $15 \mathrm{~g}$ of PF127 $30 \mathrm{~mL}$ of acetone trailed by precipitation in chilled hexane. Thus, obtained precipitate was lyophilized and stored at room temperature. Furthermore, $2 \mathrm{~g}$ of CDI was dissolved in $15 \mathrm{~mL}$ of anhydrous DMSO, $10 \mathrm{~g}$ of purified PF127 was dissolved in $15 \mathrm{~mL}$ of anhydrous DMSO was added dropwise to above solution over $30 \mathrm{~min}$ under constant stirring. The mixture was permitted to stir for $12 \mathrm{~h}$. The resultant solution was dispensed into an excess of cold diethyl ether to precipitate PF127-CDI adduct and to remove unreacted CDI. This process was repeated several times to remove unreacted CDI and the sample was vacuum dried and collected as a white powder.

\section{Synthesis of amino-terminated Pluronic F127 (PF127- $\mathrm{NH}_{2}$ )}

Solution of $12.7 \mathrm{~g}$ of PF127-CDI adduct dissolved in anhydrous DMSO was added dropwise to excess of diethylene glycol bis(3-aminopropyl)ether at ambient temperature over $30 \mathrm{~min}$. The solution was stirred for $24 \mathrm{~h}$. Purification of diethylene glycol bis(3-aminopropyl) ether modified PF127 (PF127- $\mathrm{NH}_{2}$ ) was brought about by dispensing solution in excess of chilled diethyl ether. Precipitation step was repeated several times to eliminate unreacted diethylene glycol bis(3 aminopropyl)ether. The sample was further 
purified by dialysis using $6 \mathrm{KDa}$ membrane against water (Batrakova et al. 2005).

\section{Synthesis of foliate-conjugated Pluronic F127 (PF127-FA)}

PF127FA was synthesized using EDC and NHS zero length cross linkers (Saul et al. 2003). Briefly, PF127- $\mathrm{NH}_{2}$ (500 mg, $0.079 \mathrm{mM}$ ), folic acid (105 mg, $0.237 \mathrm{mM}$ ), NHS (60 mg, $0.522 \mathrm{mM})$, and EDC (108 mg, $0.522 \mathrm{mM}$ )were dissolved in $10 \mathrm{~mL}$ of DMSO. The mixture was stirred in an inert atmosphere in dark at room temperature for $24 \mathrm{~h}$. The reaction mixture was diluted with water and dialysed against distilled water for 2 days.

\section{Synthesis of nanocomposites}

Aqueous solutions of $0.1 \mathrm{M} \mathrm{Fe}(\mathrm{III})(100 \mathrm{~mL})$ and $0.1 \mathrm{M}$ $\mathrm{Fe}$ (II) $(150 \mathrm{~mL})$ were mixed and heated to $80{ }^{\circ} \mathrm{C}$, stirred at $3000 \mathrm{rpm}$ under an inert atmosphere. Furthermore, dropwise addition of $30 \mathrm{mLof}$ ammonia $(5 \mathrm{M})$ was brought about, over $3 \mathrm{~min}$. To this reaction mixture, $300 \mu \mathrm{L}$ of oleic acid was added and allowed to stir for $20 \mathrm{~min}$ to obtain oleic acid coated magnetic nanoparticles (OAMNP). The product was washed by magnetic decantation and lyophilized.

PF127 and PF127FA, in 9:1 ratio, were dissolved in water (making total weight of $50 \mathrm{mg}$ ). To PF127 solution, $10 \mathrm{mg}$ of OAMNP suspended in chloroform was added. The components were sonicated to obtain OAMNPPF127FA. The particles obtained were washed 3 times using ultracentrifugation $\left(30,000 \mathrm{rpm}\right.$ for $20 \mathrm{~min}$ at $\left.10{ }^{\circ} \mathrm{C}\right)$ with nitrogen purged milli-Q water.

\section{Nanoparticles physical and chemical characterisation}

Fourier transform infrared spectroscopy (FTIR) was recorded by Thermo Nicolet 8700 , USA. Tiny amount of a sample was mixed with $\mathrm{KBr}$ to make a pellet. Samples were scanned in the range of $4000-500 / \mathrm{cm}$.

$\mathrm{H}$ nuclear magnetic analysis of PF127- $\mathrm{NH}_{2}$ and PF127FA was conducted by dissolving sample in DMSO- $\mathrm{d}_{6}$ and measured using JEOL JNM-ECZ400S, USA. The analysis was performed with help of Delta 5.0.5 software.

UV-visible spectrophotometric analysis was performed to confirm conjugation and quantitatively measure FA content. A known quantity FA was dissolved in DMSO and diluted to different ratios to generate standard graph at $360 \mathrm{~nm}$ using Hitachi U-2900 spectrophotometer.

The hydrodynamic size and zeta potential of nanocomposites were scanned by dispersing $1 \mathrm{mg}$ of the sample in $10 \mathrm{~mL}$ of Milli-Q water. The hydrodynamic size was measured at $25{ }^{\circ} \mathrm{C}$ using polystyrene zeta-potential cuvette.
Zeta-potential analysis was carried out by injecting sample into graphite electrode zeta-potential cuvette. Particle size and zeta-potential analysis were conducted with Horiba, SZ-100.

A droplet of OAMNPPF172FA nanoparticles (an aqueous dispersion) was placed on a carbon-coated copper TEM network and was permitted to air dry. Particles were imaged using a Philips 201 TEM. The NIH ImageJ software was used to calculate the average particle size from the TEM photomicrograph. Sizes of 20 particles were measured to calculate the average particle diameter.

The XRD analysis of OAMNPPF172FA powder was carried out using a Bruker AXS D8 Advance. The parameters chosen for the measurement were $2 \theta$ steps of $0.02^{\circ}, 6 \mathrm{~s}$, and $2 \theta$ range from $20^{\circ}$ to $80^{\circ}$.

Thermogravimetric analysis (TGA) was performed for pure OA, MNP, OAMNP, and OAMNPPF127FA by heating $600{ }^{\circ} \mathrm{C}$ at a ramp rate of $10^{\circ} \mathrm{C} / \mathrm{min}$ under nitrogen atmosphere (SDT Q600, USA.).

The magnetization and demagnetization profiles of OAMNP and OAMNPPF127FA were measured at $25^{\circ} \mathrm{C}$ at $15 \mathrm{kOe}$ applied magnetic field using, Lakeshore VSM 7410, vibrating sample magnetometer (VSM).

\section{Drug entrapment efficiency and in-vitro drug release}

The engineered nanocomposites were exploited as a carrier of hydrophobic chemotherapeutic agents PTX and CUR. The loading of PTX and CUR in nanocomposites was done as reported previously (Jain et al. 2008). $50 \mathrm{mg}$ of the OAMNPPF127FA was dispersed in $25 \mathrm{~mL}$ of Milli-Q water and was sonicated for $2 \mathrm{~min}$. Solution $5 \mathrm{mg}$ of PTX and $5 \mathrm{mg}$ of CUR was dissolved in $5 \mathrm{~mL}$ of DCM was added dropwise to OAMNPPF127FA dispersion over $3 \mathrm{~h}$. The solution was allowed to stir for $12 \mathrm{~h}$ at room temperature in dark. This allows the partitioning of the drug into the hydrophobic regions of OA and PPO moiety of PF127 surrounding the $\mathrm{Fe}_{3} \mathrm{O}_{4}$ nanoparticles. The un-partitioned drug was removed by centrifugation at $30,000 \mathrm{rpm}$ (Beckman Coulter LT optima 60) for $30 \mathrm{~min}$ at $10^{\circ} \mathrm{C}$. The pellets of PTX and CUR loaded OAMNPPF127FA (PTX-CUR-OAMNPPF127FA) resuspended in a minimum quantity of water was lyophilized and stored at $4{ }^{\circ} \mathrm{C}$.

The encapsulation efficiency (EE) and loading content (LC) of PTX and CUR in OAMNPP127FA were determined using Eqs. (1) and (2):

$$
\begin{aligned}
& \mathrm{DL} \%=\frac{\text { Weight of drug in NP }}{\text { Weight of nanoparticle }} \times 100, \\
& \mathrm{EE} \%=\frac{\text { Weight of drug in NP }}{\text { Weight of drug fed }} \times 100 .
\end{aligned}
$$


The drug release study was performed by centrifugation method (Wallace et al. 2012). $1 \mathrm{mg} / \mathrm{mL}$ of sample was suspended in PBS pH 7.4 with $0.5 \%$ tween 80 . At specific time intervals, sample was centrifuged at $30000 \mathrm{rpm}$ for $30 \mathrm{~min}$ and the supernatant was analyzed for drug content using UV-Vis spectrophotometer at $200 \mathrm{~nm}$ and $421 \mathrm{~nm}$ for paclitaxel and curcumin, respectively.

\section{Hemolysis assay}

A biomaterial with intravenous route of administration should be considered for compatibility with blood. To assess the hemocompatibility of nanocomposites, hemolysis assay was performed (Slowing et al. 2009). To assess hemocompatibility, spectrophotometer-based hemolysis assay was performed. The blood sample was collected from a healthy donor in an EDTA treated vial. Erythrocytes harvested by centrifugation at $2000 \mathrm{rpm}$ (Eppendorf, 5804R) for 5 min at $4{ }^{\circ} \mathrm{C}$. The pellet was gently washed multiple times with $\mathrm{PBS}$ at $\mathrm{pH} 7.4$ by centrifugation and resuspended in the PBS to make 4\% erythrocytes concentration. $1 \mathrm{~mL}$ of erythrocytes suspension was mixed with $1 \mathrm{~mL}$ of nanoparticles $(25-400 \mu \mathrm{g})$ and incubated for $1 \mathrm{~h}$ at $37^{\circ} \mathrm{C}$ under gentle agitation. After incubation, the cells were centrifuged to settle the blood cells. The supernatant was analyzed for released hemoglobin photometric analysis (Hitachi, U-2900) at $540 \mathrm{~nm} .1 \mathrm{~mL}$ of erythrocytes and $1 \mathrm{~mL}$ of PBS was used as a control for zero hemolysis. $1 \mathrm{~mL}$ of erythrocyte and $1 \mathrm{~mL}$ of PBS with $1 \%$ Triton $\mathrm{X}$ was used as $100 \%$ hemolysis. The erythrocyte lysis percentage was calculated according to the following equation:

Percentage hemolysis

$$
=\frac{\text { Absorbance }_{\text {Sample }}-\text { Absorbance }_{\text {Blank }}}{\text { Absorbance }_{100 \% \text { Lysis }}-\text { Absorbance }_{\text {Blank }}} \times 100 .
$$

\section{In-vitro cytotoxicity assay}

To assess the cytotoxic effects of Blank OAMNPPF127FA, PTX-CUR-OAMNPPF127, PTX-CUR-OAMNPPF127FA, and PTX-CUR-OAMNPPF127FA nanocomposites under magnetic field was determined using 3-[4,5-dimethylthiazol2-yl]-2,5-diphenyl tetrazolium bromide (MTT) cell viability assay. 96 well assay plates were seeded with MCF-7 cells at a density of 5000 cells per well. After $24 \mathrm{~h}$, the cells were treated with $0.01,0.1,1,10$, and $100 \mu \mathrm{g} / \mathrm{mL}$ concentrations of PTX-CUR, Blank OAMNPPF127FA, PTX-CUR-OAMNPPF127, and PTX-CUR-OAMNPPF127FA. To study the cell viability of PTX-CUR-OAMNPPF127FA under the magnetic field, cells were grown under $0.05 \mathrm{~T}$ magnet positioned under wells. After incubating for $48 \mathrm{~h}$, the viability of cell was determined by adding dye solution $(50 \mu \mathrm{l})$ to each well. Plates were incubated for $4 \mathrm{~h}$ at $37^{\circ} \mathrm{C}$ in $5 \% \mathrm{CO}_{2}$ atmosphere. Purple formazan crystals were solubilized in $100 \mu \mathrm{l}$ of DMSO. Furthermore, absorbance was noted at $540 \mathrm{~nm}$.

\section{Cellular uptake}

Uptake of nanocomposites was determined by quantifying iron content in the cell by means of atomic absorption spectra (AAS) (Prijic et al. 2010; Dinda et al. 2012). MCF-7 were seeded in 6-well plates, at $7.2 \times 10^{6}$ cells per well. Upon attainment confluence, growth media were swapped with $2 \mathrm{~mL}$ of OAMNPPF127 and OAMNPPF127FA suspension culture medium with (iron content of $200 \mu \mathrm{g} / \mathrm{mL}$ ). Plates were incubated at $37{ }^{\circ} \mathrm{C}$ and $5 \% \mathrm{CO}_{2}$ for duration of 60 and 240 min. Post-incubation cells were trypsinized and washed with DPBS to make sure thorough removal of media and remaining nanoparticles. Cells were collected by centrifugation and digested with $1 \mathrm{~mL}$ of $\mathrm{HCl}$. After digestion, a 1:4 dilution in $\mathrm{HCl}(0.1 \mathrm{M})$ was measured for iron content by AAS.

\section{Statistics}

SPSS 20 was used to statistically analyzed for Standard mean and standard deviation for MTT assay, drug release study, and cellular uptake.

\section{Results}

\section{Synthesis OAMNPP127FA nanocomposites}

FA-modified PF127 was prepared in first by modifying PF127 with homofunctionalized diethylene glycol moiety using CDI reagent followed by decoration of FA using zero length cross linkers (EDC and NHS). The brief schematic representation of synthesis is shown in Fig. $1 . \mathrm{Fe}_{3} \mathrm{O}_{4}$ synthesis was brought about by precipitating iron (II) and iron (III) by ammonia. Yellow-colored iron salts' solution changed to black upon addition of ammonia. Black-colored nanocrystals thus formed were coated with oleic acid. Modification with oleic acid leads to greasy aggregations. Furthermore, the addition of Pluronic F127 and Pluronic F127 FA brought about good dispersity and solubility to the composite. The $\mathrm{N}_{2}$ atmosphere was maintained throughout the reaction to evade oxidation of nanoparticles. The nanocomposite centers iron oxide with subsequent hydrophobic and hydrophilic compartments. The nanocomposites, PTX-CUR-OAMNPPF127FA, were prepared, as shown in the graphical abstract. 


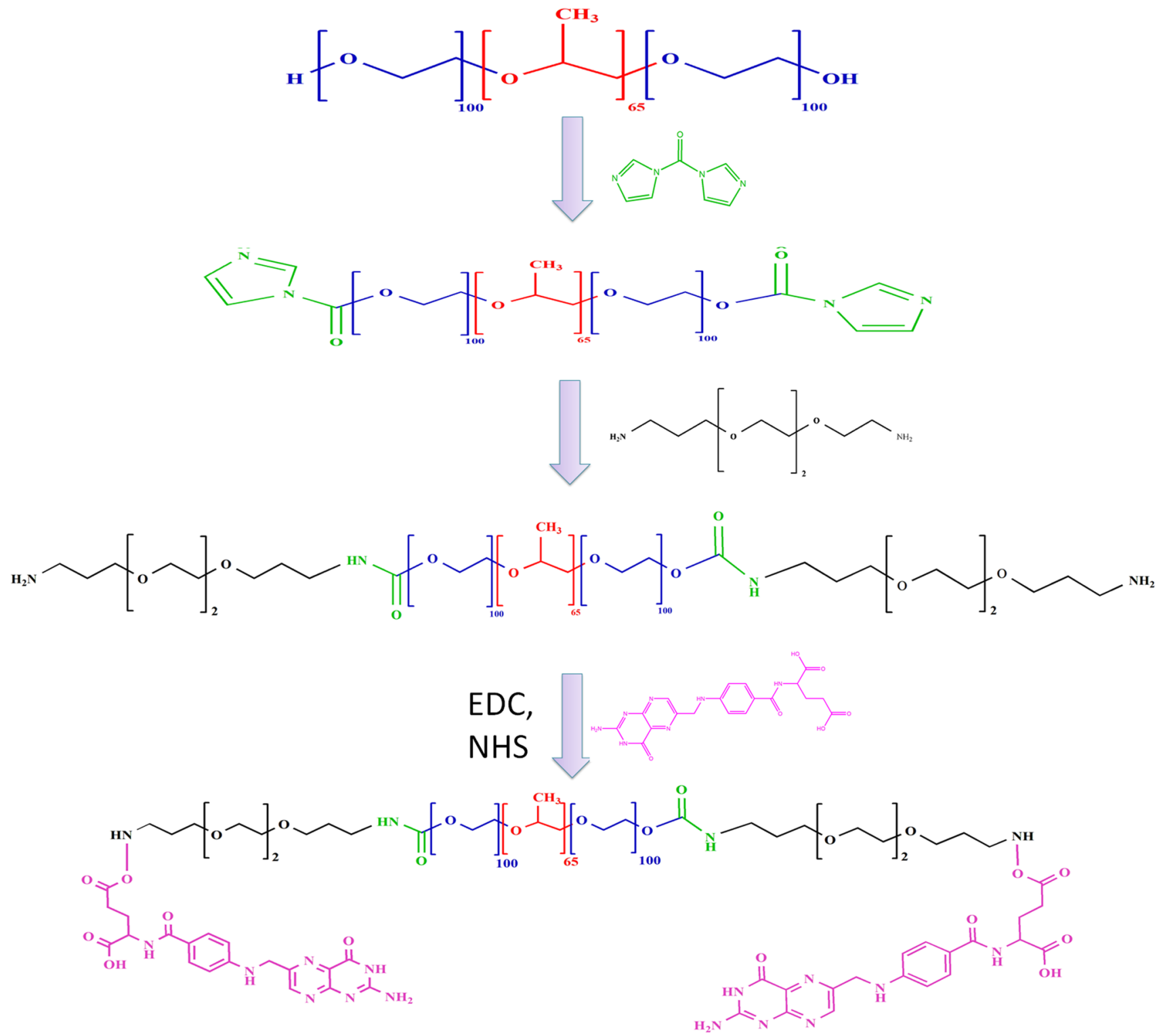

Fig. 1 Schematic representation of PF127FA synthesis

\section{Fourier transform infrared spectra}

FTIR spectra of Pure OA, MNP, OAMNP, PF127-NH2, PF127FA, and OAMNPPF127FA are shown in Fig. 2. FTIR spectra of pure OA express prominent peak at $1705 / \mathrm{cm}$ credible to the $\mathrm{C}=\mathrm{O}$ stretch. $3000 / \mathrm{cm}$ broad peak is due to the -OH stretch. $2853 / \mathrm{cm}$ and $2922 / \mathrm{cm}$ peaks correspond to the $\mathrm{CH}_{2}$ symmetric and $\mathrm{CH}_{2}$ asymmetric stretching, respectively. Spectra of OAMNP, however, display no peaks corresponding to $\mathrm{C}=\mathrm{O}$ stretch. The peaks at $2853 / \mathrm{cm}$ and $2921 / \mathrm{cm}$ are owed to $\mathrm{CH}_{2}$ groups of chemisorbed OA. The presence of peak at $1110.42 / \mathrm{cm}$ in $\mathrm{PF} 127-\mathrm{NH}_{2}$ sample corresponds to $\mathrm{C}-\mathrm{N}$ stretching. Spectra of OAMNPPF127FA present peaks around $3450 / \mathrm{cm}$ is due to $\mathrm{NH}_{2}$ groups, which are merged with hydroxyl peaks. Peaks at $1693 / \mathrm{cm}$ and $1638 / \mathrm{cm}$ are due to carbonyl stretching peaks of folic acid. Peaks at 1606/ $\mathrm{cm}$ and $1577 / \mathrm{cm}$ are due to a $p$-aminobenzoyl-L-glutamic acid moiety of folic acid. Spectra of OAMNPPF127FA show peaks that are in PF127FA and OAMNP.

\section{NMR}

1H NMR spectrum (400 MHz, DMSO-D6) of PF127-NH2 illustrated the peaks at $\mathrm{d}(\mathrm{ppm})=1.02-0.95(\mathrm{~d}, 3 \mathrm{H} \times 65$, $-\mathrm{CH}_{3}$ of PPO), 3.61-3.26 (m, $3 \mathrm{H} \times 65,4 \mathrm{H} \times 200,2 \mathrm{H} \times 12$, $-\mathrm{CH}_{2} \mathrm{CHO}$ of PPO, $-\mathrm{CH}_{2} \mathrm{CH}_{2} \mathrm{O}-$ and $-\mathrm{OCH}_{2} \mathrm{CH}_{2} \mathrm{O}-$ of PEO), $2.73\left(\mathrm{t}, 2 \mathrm{H} \times 2,-\mathrm{CH}_{2} \mathrm{~N}\right), 3.19\left(\mathrm{q}, 2 \mathrm{H} \times 2, \mathrm{CNCH}_{2}-\right)$ (Fig. 3a). 


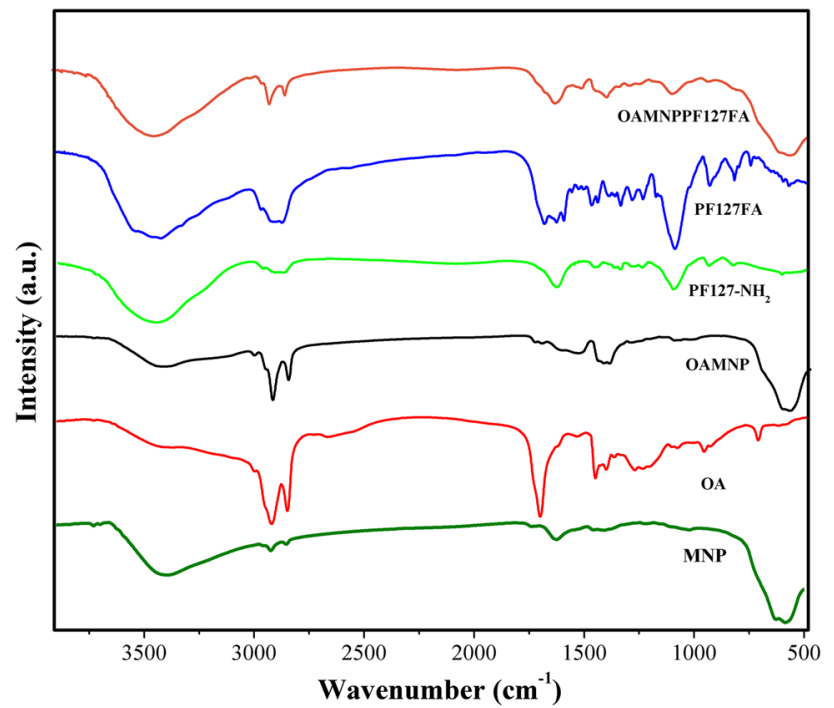

Fig. 2 Fourier transform infrared spectra of MNP, OA, OAMNP, PF127NH 2 , PF127FA, and OAMNPPF127FA

1H-NMR (400 MHz, DMSO-D6)of PF127FA 1.09 (d, $3 \mathrm{H} \times 65,-\mathrm{CH}_{3}$ of PPO), $2.63\left(\mathrm{t}, 2 \mathrm{H} \times 2,-\mathrm{CH}_{2} \mathrm{~N}\right), 2.93(\mathrm{~m}$, $2 \mathrm{H}, \mathrm{C} 22 \times \mathrm{H} 2$ of folic acid), $3.28\left(\mathrm{q}, 2 \mathrm{H} \times 2, \mathrm{CNCH}_{2}-\right)$, 3.29-3.62 (m, $3 \mathrm{H} \times 65,4 \mathrm{H} \times 200,2 \mathrm{H} \times 12,-\mathrm{CH}_{2} \mathrm{CHO}$ of $\mathrm{PPO},-\mathrm{CH}_{2} \mathrm{CH}_{2} \mathrm{O}-$ and $-\mathrm{OCH}_{2} \mathrm{CH}_{2} \mathrm{O}-$ of $\left.\mathrm{PEO}\right), 4.43$ (d, $2 \mathrm{H}$, $\mathrm{C} 9 \times \mathrm{H} 2$ of folic acid), $6.60(\mathrm{~d}, 2 \mathrm{H}$, aromatic protons of folic acid), 7.56-7.58 (d, 2H, aromatic protons of folic acid), and 8.59 (s, 1H, C7 $\times$ H of folic acid) (Fig. 3b).

\section{UV spectra}

UV-visible spectra scanned in the range of 300-500 nm of P127-NH2, FA, and P127-FA are shown in Fig. 4. No prominent peaks were noticed in $\mathrm{P} 127-\mathrm{NH}_{2}$ spectra. The prominent peak at $320 \mathrm{~nm}$ and $380 \mathrm{~nm}$ is seen in FA sample. Similar peaks were seen in the case of P127-FA. Furthermore, the percentage of conjugation was determined using standard curve, and was found to be $84.34 \%$.

\section{Particle size and zeta potential}

The hydrodynamic size, zeta potential, and polydispersity index of MNP and OAMNPPF127FA are tabulated in Table 1. MNP sample shows higher size and polydispersity index than OAMNPPF127FA. Sample OAMNPPF127FA showed much higher zeta potential in contrast to MNP. Transmission electron microscopy, which measures the size of the magnetic core, measure average particle size as $12.5 \mathrm{~nm}$ (Fig. 5).

\section{X-ray diffraction}

The study of X-ray powder diffraction (XRD) was carried out to confirm the presence of nanocrystalline and the

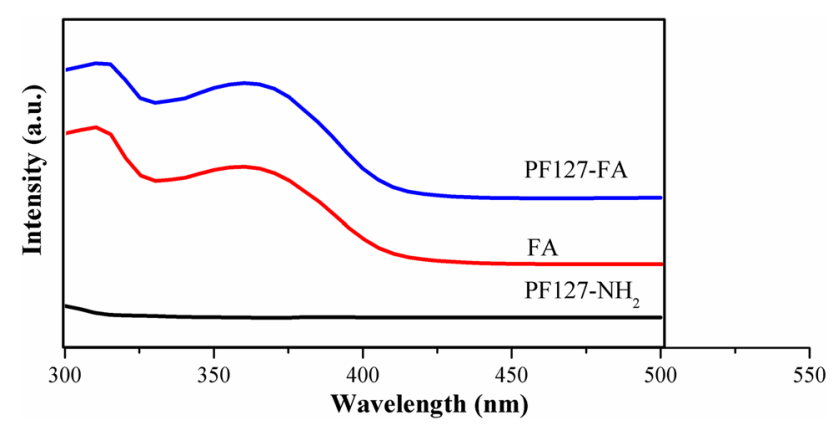

Fig. 4 UV-visible spectra of PF127- $\mathrm{NH}_{2}$, FA, and PF127- $\mathrm{NH}_{2}$
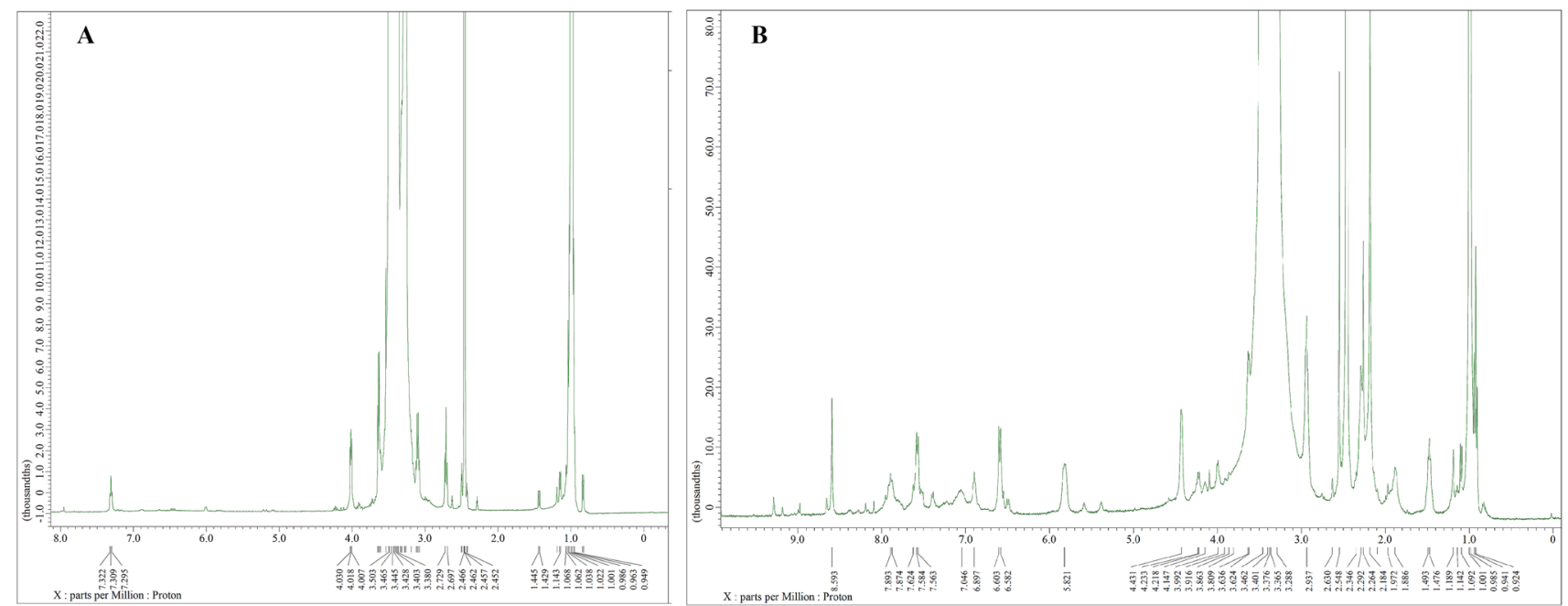

Fig. 3 NMR spectra of PF127- $\mathrm{NH}_{2}$ (a) and PF127-FA (b) 
Table 1 Size, zeta potential, and polydispersity index of MNP and OAMNPPF127FA

\begin{tabular}{lrll}
\hline Sample & Size $(\mathrm{nm})$ & $\begin{array}{l}\text { Zeta potential } \\
(\mathrm{mV})\end{array}$ & $\begin{array}{l}\text { Polydis- } \\
\text { persity } \\
\text { index }\end{array}$ \\
\hline MNP & $124.2 \pm 9.2$ & -2.1 & 2.313 \\
OAMNPPF127FA & $94.2 \pm 6.3$ & -25.5 & 1.011 \\
\hline
\end{tabular}

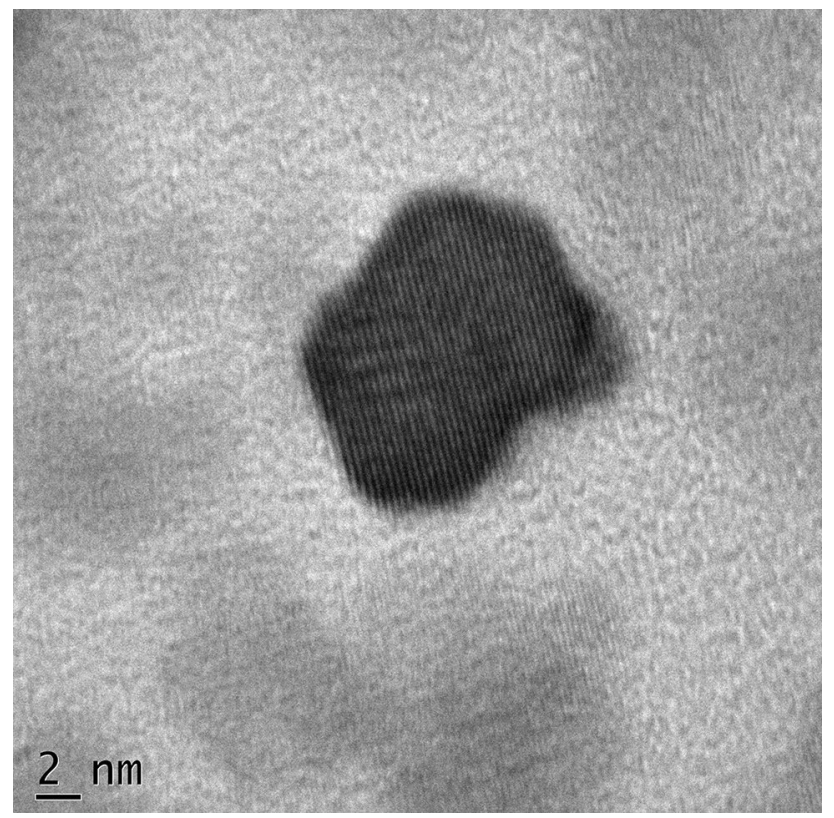

Fig. 5 Transmission electron micrograph of OAMNPPF127FA

phase of the synthesized materials. The recorded XRD pattern is shown in Fig. 6. Here, we observed strong and sharp peaks, which reveal that the synthesized nanoparticles are crystallized in nature. The Bragg's reflection angles were obtained at $2 \theta=30.09{ }^{\circ} \mathrm{C}, 35.44{ }^{\circ} \mathrm{C}$, $37.07{ }^{\circ} \mathrm{C}, 43.07{ }^{\circ} \mathrm{C}, 56.96{ }^{\circ} \mathrm{C}, 62.55^{\circ} \mathrm{C}$, and $74.0{ }^{\circ} \mathrm{C}$ corresponding to (220), (311), (222), (400), (511), (440), and (533) planes which are compared with the standard joint committee on powder diffraction standards (JCPDS) data and it is well matched with data no. 870245 . It is confirmed that the material is iron oxide $\mathrm{Fe}_{3} \mathrm{O}_{4}$ having the face-centered-cubic structure of $\mathrm{Fe}_{3} \mathrm{O}_{4}$. Some of the observed sharp and intense peaks suggest the strong X-ray scattering centers in the crystalline phase.

\section{Thermogravimetric analysis (TGA)}

Thermogravimetric analysis results of pure OA, MNP, OAMNP, and OAMNPP127FA are shown in Fig. 7. Pure OA started decomposing at $200{ }^{\circ} \mathrm{C}$, whereas the OAMNP shows steady mass around $350{ }^{\circ} \mathrm{C}$. OAMNP and OAMNPPF127 showed an overall loss of $20.2 \%$ and $44.5 \%$,

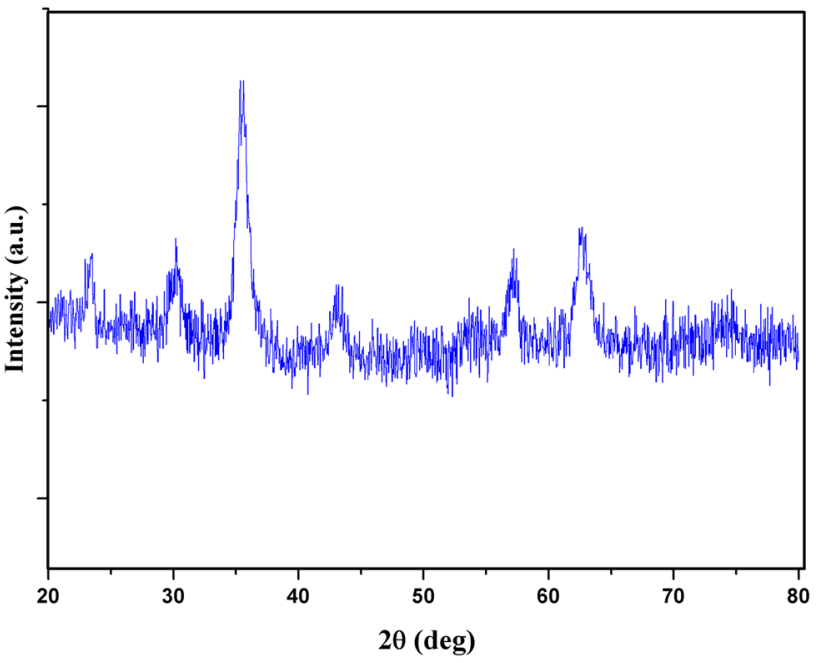

Fig. 6 X-ray powder diffraction pattern of OAMNPPF127FA

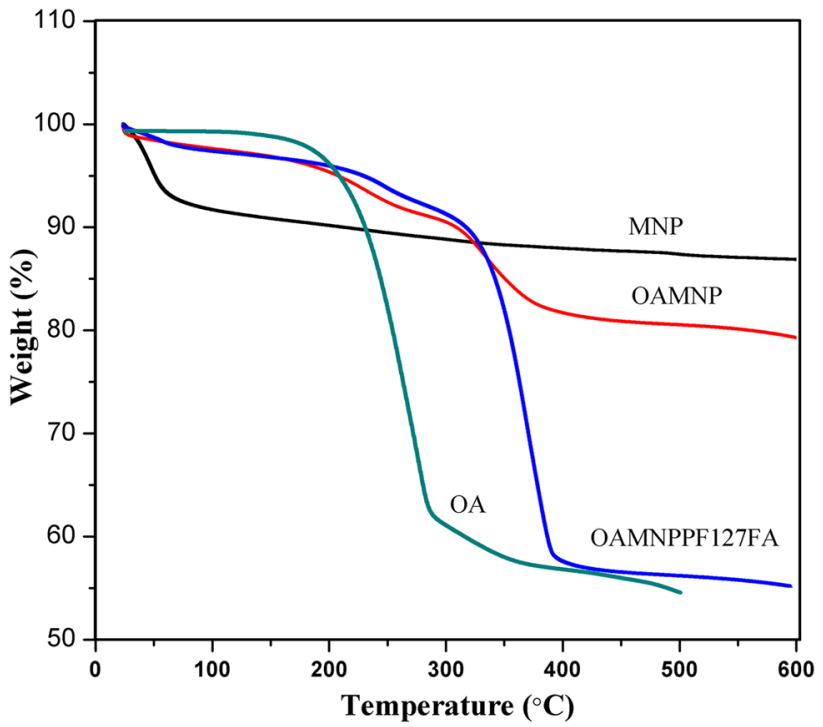

Fig. 7 Thermogravimetric analysis of pure OA, MNP, OAMNP, and OAMNPP127FA

respectively. Furthermore, mass loss witnessed at around $100{ }^{\circ} \mathrm{C}$ for MNP and OAMNPP127FA sample was not prominent. However, in the case of OAMNP, no mass loss was seen at around $100{ }^{\circ} \mathrm{C}$.

\section{Vibrating sample magnetometry (VSM)}

Magnetization and demagnetization curve of OAMNP and OAMNPP127FA samples are shown in Fig. 8. Magnetic saturation $\left(M_{\mathrm{s}}\right)$ value of $49.56 \mathrm{emu} / \mathrm{g}$ and $39.04 \mathrm{emu} / \mathrm{g}$ was exhibited by OAMNP and OAMNPP127FA, respectively. Neither OAMNP nor OAMNPP127FA showed coercivity or magnetic remanence. 


\section{Drug entrapment efficiency and in-vitro drug release}

Nanocomposites PTX-CUR-OAMNPPF127 had drug content of $9.42 \%$, of which $3.47 \%$ was paclitaxel and $5.95 \%$ was curcumin. Encapsulation efficiency of paclitaxel and curcumin was 34.7 and 59.5, respectively. Furthermore, both drugs displayed sustained release behavior (Fig. 9) over $75 \mathrm{~h}$.

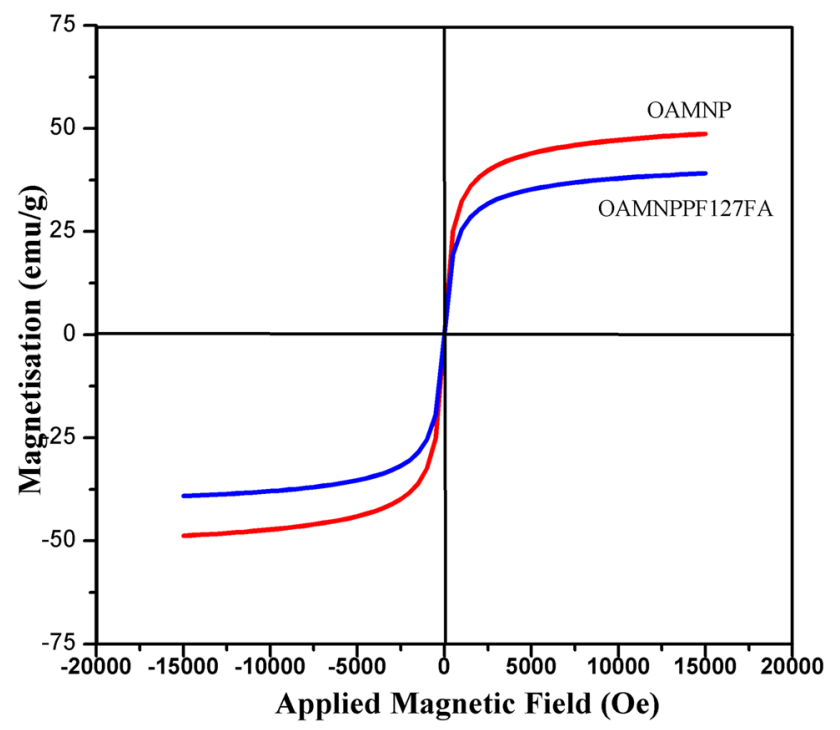

Fig. 8 Magnetic hysteresis analysis of OAMNP and OAMNPP127FA

\section{Hemolysis assay}

Haemocompatibility was measured by hemolysis assay. The amount of hemoglobin released from blood cells after incubation was determined photometrically. Figure 10 shows hemolytic activity exhibited by OAMNPP127FA nanocomposites at various concentrations. Concentration measured by UV-visible spectrophotometer at $521 \mathrm{~nm}$ indicated a total of $4.1 \%$ hemolysis at $400 \mathrm{mg} / \mathrm{mL}$ concentration.

\section{In-vitro cytotoxicity of PTX-CUR-OAMNPP127FA}

MTT cell viability assay was performed for $48 \mathrm{hr}$ to evaluate the cytotoxic property. Samples PTX, CUR, OAMNPPF127FA, PTX-CUR-OAMNPPF127FA, and PTXCUR-OAMNPPF127FA under magnetic field at against MCF-7 cell lines and the results thus obtained are presented in Fig. 11. The determined $\mathrm{IC}_{50}$ values of the PTX, CUR, Blank OAMNPPF127FA, PTX-CUR-OAMNPPF127, PTXCUR-OAMNPPF127FA, and PTX-CUR-OAMNPPF127FA above magnetic field for $48 \mathrm{~h}$ were $0.002,0.9101,1198.67$, $9.99,4.12$, and $0.7377 \mu \mathrm{g} / \mathrm{mL}$, respectively.

\section{Nanoparticle uptake by MCF-7 cells}

Quantitative nanoparticle uptake was determined by assessing iron content in the cell by AAS is depicted in Fig. 12. OAMNPPF127 showed the iron concentration of $5.02 \mathrm{pg} / \mathrm{cell}$ and $13.95 \mathrm{pg} / \mathrm{cell}$ in the absence of magnetic field at 1 and $4 \mathrm{~h}$ of incubation. Similarly, $7.777 \mathrm{pg} /$ cell and $16.8 \mathrm{pg} / \mathrm{cell}$ concentration of iron was analyzed at $1 \mathrm{~h}$ and $4 \mathrm{~h}$ incubation, respectively, in the presence
Fig. 9 PTX and CUR release profile from OAMNPPPF127FA

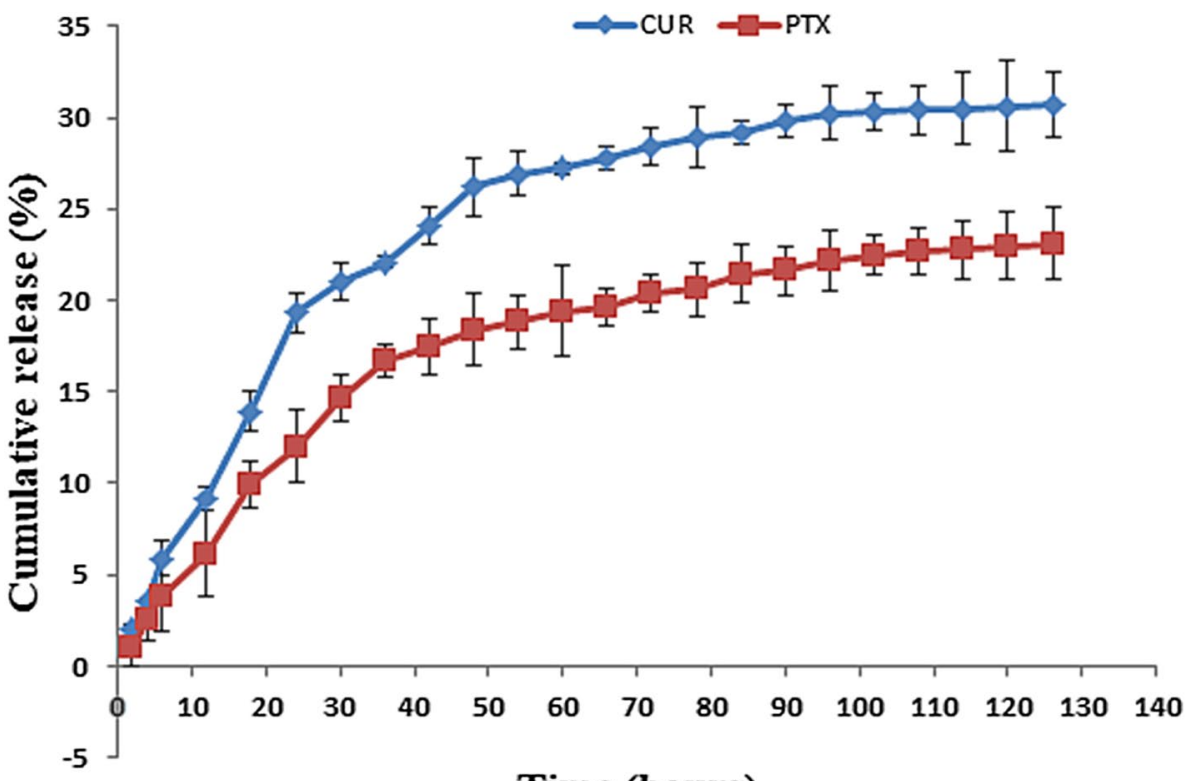

Time (hours) 
Fig. 10 Haemolysis assay of OAMNPPF127FA at various concentrations
Fig. 11 Cell viability assay of PTX, CUR, OAMNPPF127FA, PTX-CUR-OAMNPPF127FA, and PTX-CUR-OAM-

NPPF127FA under magnetic field at against MCF-7 cells
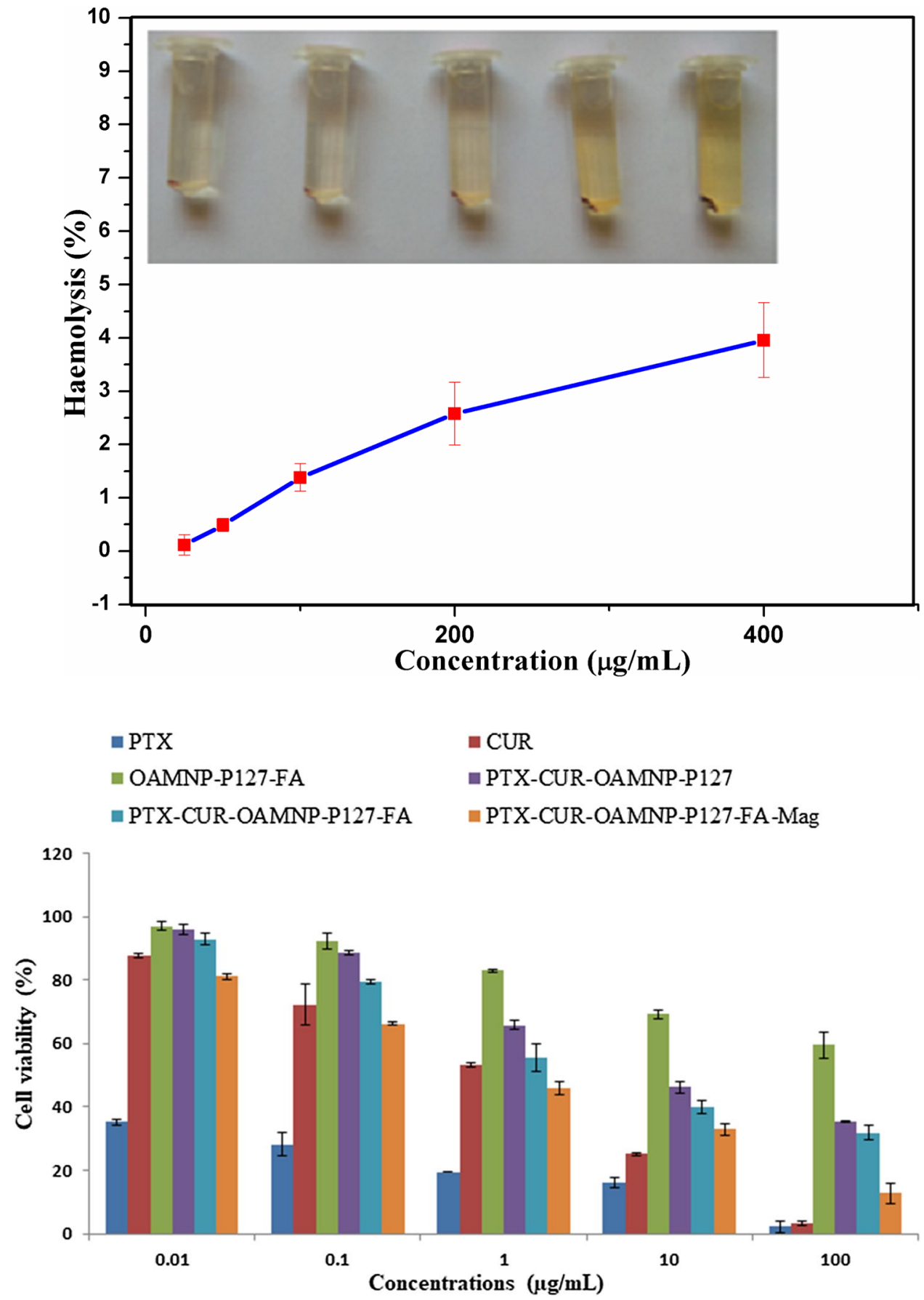

of a magnetic field. OAMNPPF127FA sample displayed the iron concentration of $6.874 \mathrm{pg} / \mathrm{cell}$ and $18.4 \mathrm{pg} / \mathrm{cell}$ at $1 \mathrm{~h}$ and $4 \mathrm{~h}$ incubation in the absence of magnetic field. The presence of magnetic field and nanocomposites under magnetic field at $1 \mathrm{~h}$ incubation revealed the iron concentration of $2.78 \mathrm{pg} / \mathrm{cell}$ and $4.19 \mathrm{pg} / \mathrm{cell}$ in occurrence of an exterior magnetic field. At $4 \mathrm{~h}$ incubation, iron content of $12.31 \mathrm{pg} / \mathrm{cell}$ and $21.2 \mathrm{pg} / \mathrm{cell}$ was noticed in the absence and occurrence of a magnetic field, respectively.

\section{Discussion}

In this work, we have synthesized OAMNPPF127FA, wherein iron oxide nanoparticle core is stabilized by OA and further coated with PF127FA and PF127 in a specific ratio. OAMNPPF127FA is a water dispersible nanoparticle-based formulation to address the often faced problem of aqueous insolubility and systemic toxicity. Lack of aqueous solubility hinders the bioavailability 
Fig. 12 Cellular uptake of OAMNPPF127 and OAMNPPF127FA at 1 and $4 \mathrm{~h}$ incubation

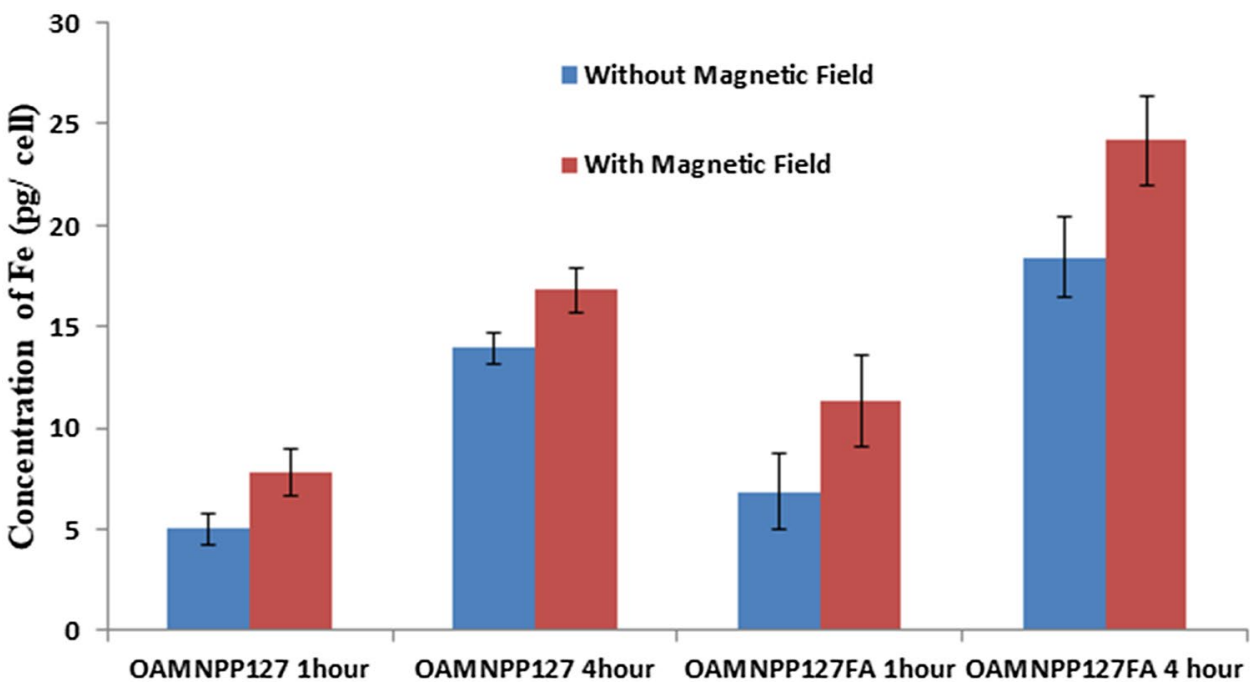

thus extensively hampering the effectiveness of the drug. Diethylene glycol bis(3-aminopropyl) ether is a diethylene glycol derivative and is not reported previously in the literature. Magnetic nanoparticles can be passively targeted with the external magnetic field to the site of cancer, which increases the concentration at the site of action (Pankhurst et al. 2003). We have thus constructed a nanostructure that can transport hydrophobic drugs and has the ability to concentrate to a specific area by the external magnetic field and actively targeted with the help of folic acid ligand. Diethylene glycol bis(3-aminopropyl) ether, a diethylene glycol derivative, has not been used previously for amine functionalization of PF127. We theorize that the formulation allows partitioning hydrophobic drug in the hydrophobic case neighbouring iron oxide nanoparticles.

In FTIR spectra, the presence of peaks at $2853 / \mathrm{cm}$ and $2922 / \mathrm{cm}$ indicates the presence of OA on MNP. The presence of $\mathrm{C}=\mathrm{O}$ peak in $\mathrm{OA}$, but absence in OAMNP confirmed the chemisorption of OA (Raut et al. 2010). The $1110.42 / \mathrm{cm}$ peak corresponds to $\mathrm{C}-\mathrm{N}$ starching, indicating the presence of the amine group. Conjugation of folic acid to PF127FA was confirmed by peaks $1693 / \mathrm{cm}$ and $1638 / \mathrm{cm}$, which are due to carboxyl groups of FA and peaks at $1606 / \mathrm{cm}$ and $1577 / \mathrm{cm}$ are due top-aminobenzoyl-L-glutamic acid moiety of folic acid, demonstrating conjugation of FA to PF127$\mathrm{NH}_{2}$ (Li et al. 2012; Hiremath et al. 2018).

NMR spectra further confirm the conjugation of diethylene glycol bis(3-aminopropyl) ether in PF127- $\mathrm{NH}_{2}$ and folic acid to PF127- $\mathrm{NH}_{2}$. UV-visible spectra of PF127- $\mathrm{NH}_{2}$ showed no peaks. However, peaks similar to peaks of FA were seen in PF127FA sample, indicating successful conjugation of FA to PF127- $\mathrm{NH}_{2}$ (Zhang et al. 2011). Further quantitatively analysis revealed $\sim 85 \%$ of conjugation.

The hydrodynamic size of MNP was found to be bigger than OAMNPPF127FA. High polydispersity index profile of MNP indicates large size distribution. This may be is due to the agglomeration of particles. The agglomeration might be owing to the absence of capping agent and smaller zeta potential (Lu et al. 2007). Zeta potential is a net superficial charge on the on nanoparticle, which is an indication degree of repulsion between particles in of similar charge in suspension. Thus, greater the negative or positive value of zeta potential, lesser the aggregation behavior of the particles (Arya et al. 2011). OAMNPPF127FA displayed good valve of zeta potential and low polydispersity index and, however, showed zeta potential of $-25.5 \mathrm{mV}$ and indicating good aqueous stability. Low polydispersity index indicates a narrow size distribution profile hence lack of agglomerations. TEM images show the average particle diameter size of $12.54 \mathrm{~nm}$. The obvious difference is due to coating and hydrodynamic size.

Percentage of components was revealed by thermogravimetric analysis. Iron oxide core was the major constituent making up $\sim 55.5 \%$ weight of nanocomposites. Unlike pure OA decomposition curve, OAMNP decomposition curve displayed study decomposition. This can be accredited to due to chemisorption of oleic acid which might have conferred the thermal stability to OA.

The thermogravimetric analysis indicates that around $20.2 \%$ of OAMNP is OA. In the case of OAMNPPF127, approximately $53 \%$ weight loss was observed which indicate that $23 \%$ of total mass is coated with PF127 and PF127FA. Not much of weight loss noticed in case of pure MNP, and slight weight loss can be accredited to chemisorbed moisture. OAMNPPF127FA and MNP samples exhibited mass loss; however, no moisture loss was observed by OAMNP. This may be due to the hydrophobic property of OAMNP, wherein carboxyl group is chemisorbed exposing hydrophobic tail, thus repelling water. 
High saturation magnetization value and super paramagnetism are of vital importance for magnetic targeting; thus, VSM analysis was performed. Super paramagnetism is a phenomenon, where nanoparticles are magnetized and completely demagnetized in the presence and absence of magnetic field, respectively. Super-paramagnetic behavior is typical for magnetic nanoparticles, since the demagnetization temperature will be less than or equal to room temperature (Wahajuddin 2012). A drop in saturation magnetization value after the coating is due to the change in iron oxide core and coating ratio (Kolhatkar et al. 2013). OAMNP and OAMNPP127FA samples exhibit magnetisation and demagnetization devoid of remanence and coercivity and thus exhibit super paramagnetism property.

Efficient drug uptake and controlled release behavior are of chief importance for a drug-delivery system (Din et al. 2017). Controlled release behavior is effective in maintaining active plasma or cancer microenvironment drug concentration (Wahajuddin 2012). Good encapsulation efficiency of $37.9 \%$ and $56.5 \%$ was exhibited by paclitaxel and curcumin, respectively. Furthermore, both drugs elicited sustained release profile (Fig. 8) over 75 h. Demonstrating OAMNPPF127FA would be excellent vehicles for hydrophobic drug loading. The in vivo applications of the biomaterial must essentially promise excellent blood compatibility (Brash 2018), such as a very low hemolytic consequence. Nanocomposites intended for biomedical application was subjected to haemolysis assay to analyze haemocompatibility (Wu et al. 2011). OAMNPPF127FA nanocomposites showed good haemocompatibility at a concentration as high as $400 \mu \mathrm{l} / \mathrm{mL}$ with $3.5 \%$ hemolysis.

MTT assay was used to assess the cytotoxicity of nanoparticles. All the samples showed increased cytotoxicity with an increase in concentration. Although OAMNPPF127FA exhibited some degree of cytotoxicity, the toxicity of drugloaded nanoparticles were much higher. This is mainly accredited to the presence of the drug in the nanoparticles. Cells were treated with PTX-CUR-OAMNPPF127 in the presence of magnetic field showed relatively lower $\mathrm{IC}_{50}$ values in contrast to the absence of a magnetic field. This can be owed to the relatively high concentration of nanoparticles at the exterior of the cell. Resulting high number of nanocomposites at proximity and eliciting higher toxicity (Plank et al. 2003). Lesser $\mathrm{IC}_{50}$ in presence of magnetic field can also attributed to higher uptake of cells by nanoparticles.

Cell uptake assay was performed to analyze the uptake of nanoparticles by MCF-7 cells. Folic acid is reported to efficiently internalize folic acid and folic acid conjugates by receptor-mediated endocytosis, and its efficiency is owed to higher of $\mathrm{Kd} \sim 10^{-10} \mathrm{M}$ (Liu et al. 2009). Results revealed that cellular uptake increased with incubation time for all the composites. Cells incubated with FA-conjugated nanocomposites displayed higher iron concentration in comparison with unconjugated nanocomposites, thus indicating the role of FA in cellular internalization of nanocomposites. Furthermore, still, higher uptake was witnessed in the presence of magnetic field indicating a positive consequence of the external magnetic field on cellular internalization.

\section{Conclusions}

The engineered nanoparticle can be prepared and loaded with hydrophobic agents, in this case, PTX and CUR. Since drug loading is due to the interaction of the hydrophobic cavity with the hydrophobic drug, it can be used with other hydrophobic drugs. PF127 and PF127FA have brought about good dispersity and optimum hydrodynamic size. Diethylene glycol bis(3-aminopropyl) ether can be used as a spacer for folic acid conjugation. The nanocomposites showed good encapsulation efficiency and release kinetics. The folic acid conjugated sample showed better cytotoxicity and higher cellular uptake. Nanocomposites showed that super-paramagnetic activity hence can be used for magnetic targeting. Further increase in cytotoxicity and cellular uptake was noticed in occurrence of external magnetic field. Nanocomposites showed good haemocompatibility and hence can be used for intravenous administration. We can anticipate the combination of multiple drugs and folic acid targeting could be employed for MDR cancer treatment.

\section{Compliance with ethical standards}

Conflict of interest Authors Chinmay G Hiremath, Geetha B. Heggnnavar, Mahadevappa Y Kariduraganavar, and Murigendra B Hiremath do not have a conflict of interest for publishing an original article entitled "Folic acid modified Pluronic coated iron oxide nanoparticles for co-delivery of Paclitaxel and Curcumin." in your journal.

Ethical approval Human blood sample was taken from healthy donor, for haemolysis assay, according to hospital ethical guidelines. Informed consent is with medical record section of hospital.

Open Access This article is distributed under the terms of the Creative Commons Attribution 4.0 International License (http://creativeco mmons.org/licenses/by/4.0/), which permits unrestricted use, distribution, and reproduction in any medium, provided you give appropriate credit to the original author(s) and the source, provide a link to the Creative Commons license, and indicate if changes were made.

\section{References}

Arya G, Vandana M, Acharya S, Sahoo SK (2011) Enhanced antiproliferative activity of Herceptin (HER2)-conjugated gemcitabine-loaded chitosan nanoparticle in pancreatic cancer therapy. Nanomed Nanotechnol Biol Med 7:859-870. https://doi. org/10.1016/j.nano.2011.03.009 
Batrakova EV, Vinogradov SV, Robinson SM et al (2005) Polypeptide point modifications with fatty acid and amphiphilic block copolymers for enhanced brain delivery. Bioconjug Chem 16:793-802. https://doi.org/10.1021/bc049730c

Brash JL (2018) Blood compatibility of nanomaterials. In: Drug delivery nanosystems for biomedical applications, Elsevier, pp 13-31. https://doi.org/10.1016/b978-0-323-50922-0.00002-x

Brigger I, Dubernet C, Couvreur P (2002) Nanoparticles in cancer therapy and diagnosis. Adv Drug Deliv Rev 54:631-651

Chauhan VP, Jain RK (2013) Strategies for advancing cancer nanomedicine. Nat Mater 12:958-962. https://doi.org/10.1038/nmat3 792

Cheung A, Bax HJ, Josephs DH et al (2016) Targeting folate receptor alpha for cancer treatment. Oncotarget 7:52553-52574. https:// doi.org/10.18632/oncotarget.9651

Din FU, Mustapha O, Qureshi OS et al (2017) Effective use of nanocarriers as drug delivery systems for the treatment of selected tumors. Int J Nanomed 12:7291-7309. https://doi.org/10.2147/ijn.s146315

Dinda A, Kumar M, Singh V et al (2012) Cellular interaction of folic acid conjugated superparamagnetic iron oxide nanoparticles and its use as contrast agent for targeted magnetic imaging of tumor cells. Int J Nanomed 7:3503. https://doi.org/10.2147/IJN.S32694

Fujita H, Ooya T, Yui N (1999) Thermally induced localization of cyclodextrins in a polyrotaxane consisting of $\beta$-cyclodextrins and poly(ethylene glycol)-poly(propylene glycol) triblock copolymer. Macromolecules. https://doi.org/10.1021/ma9814550

Ganta S, Amiji M (2009) Coadministration of paclitaxel and curcumin in nanoemulsion formulations to overcome multidrug resistance in tumor cells. Mol Pharm 6:928-939. https://doi.org/10.1021/ mp800240j

Gottesman MM, Fojo T, Bates SE (2002) Multidrug resistance in cancer: role of ATP-dependent transporters. Nat Rev Cancer 2:48-58. https://doi.org/10.1038/nrc706

Gupta AK, Gupta M (2005) Synthesis and surface engineering of iron oxide nanoparticles for biomedical applications. Biomaterials 26:3995-4021. https://doi.org/10.1016/j.biomaterials.2004.10.012

Hamzehalipour Almaki J, Nasiri R, Idris A et al (2017) Trastuzumabdecorated nanoparticles for in vitro and in vivo tumor-targeting hyperthermia of HER2+ breast cancer. J Mater Chem B 5:73697383. https://doi.org/10.1039/C7TB01305A

Hatcher H, Planalp R, Cho J et al (2008) Curcumin: from ancient medicine to current clinical trials. Cell Mol Life Sci 65:1631-1652. https://doi.org/10.1007/s00018-008-7452-4

Hiremath CG, Kariduraganavar MY, Hiremath MB (2018) Synergistic delivery of 5-fluorouracil and curcumin using human serum albumin-coated iron oxide nanoparticles by folic acid targeting. Prog Biomater 7:297-306. https://doi.org/10.1007/s40204-018-0104-3

Huang MT, Smart RC, Wong CQ, Conney AH (1988) Inhibitory effect of curcumin, chlorogenic acid, caffeic acid, and ferulic acid on tumor promotion in mouse skin by $12-O$-tetradecanoylphorbol13-acetate. Cancer Res 48:5941-5946

Huang S-J, Sun S-L, Feng T-H et al (2009) Folate-mediated chondroitin sulfate-Pluronic 127 nanogels as a drug carrier. Eur J Pharm Sci 38:64-73. https://doi.org/10.1016/j.ejps.2009.06.002

Jain TK, Richey J, Strand M et al (2008) Magnetic nanoparticles with dual functional properties: drug delivery and magnetic resonance imaging. Biomaterials 29:4012-4021. https://doi.org/10.1016/j. biomaterials.2008.07.004

Jin Y, Jia C, Huang S-W et al (2010) Multifunctional nanoparticles as coupled contrast agents. Nat Commun 1:1-8. https://doi. org/10.1038/ncomms 1042

Kang HJ, Lee SH, Price JE, Kim LS (2009) Curcumin suppresses the paclitaxel-induced nuclear factor- $\kappa \mathrm{B}$ in breast cancer cells and potentiates the growth inhibitory effect of paclitaxel in a breast cancer nude mice model. Breast J 15:223-229. https://doi.org/10 $.1111 /$ j.1524-4741.2009.00709.x
Kelemen LE (2006) The role of folate receptor $\alpha$ in cancer development, progression and treatment: cause, consequence or innocent bystander? Int J Cancer 119:243-250. https://doi.org/10.1002/ ijc. 21712

Khodabandehloo H, Zahednasab H, Ashrafi Hafez A (2016) Nanocarriers usage for drug delivery in cancer therapy. Iran J cancer Prev 9:e3966. https://doi.org/10.17795/ijcp-3966

Kolhatkar AG, Jamison AC, Litvinov D et al (2013) Tuning the magnetic properties of nanoparticles. Int J Mol Sci 14:15977-16009. https://doi.org/10.3390/ijms140815977

Koutras AK, Fountzilas G, Dafni U et al (2008) Myelotoxicity as a prognostic factor in patients with advanced breast cancer treated with chemotherapy: a pooled analysis of two randomised trials conducted by the Hellenic Cooperative Oncology Group. Anticancer Res 28:2913-2920

Kuttan R, Bhanumathy P, Nirmala K, George MC (1985) Potential anticancer activity of turmeric (Curcuma longa). Cancer Lett 29:197-202

Li G, Magana D, Dyer RB (2012) Photoinduced electron transfer in folic acid investigated by ultrafast infrared spectroscopy. J Phys Chem B 116:3467-3475. https://doi.org/10.1021/jp300392a

Lin J-J, Chen J-S, Huang S-J et al (2009) Folic acid-Pluronic F127 magnetic nanoparticle clusters for combined targeting, diagnosis, and therapy applications. Biomaterials 30:5114-5124. https://doi. org/10.1016/j.biomaterials.2009.06.004

Liu B, Pan J, Feng S-S et al (2009) Folic acid conjugated nanoparticles of mixed lipid monolayer shell and biodegradable polymer core for targeted delivery of Docetaxel. Biomaterials 31:330-338. https ://doi.org/10.1016/j.biomaterials.2009.09.036

Locasale JW (2013) Serine, glycine and one-carbon units: cancer metabolism in full circle. Nat Rev Cancer 13:572-583. https:// doi.org/10.1038/nrc3557

Lomis N, Westfall S, Farahdel L et al (2016) Human serum albumin nanoparticles for use in cancer drug delivery: process optimization and in vitro characterization. Nanomaterials 6:116. https://doi. org/10.3390/nano6060116

Longley D, Johnston P (2005) Molecular mechanisms of drug resistance. J Pathol 205:275-292. https://doi.org/10.1002/path.1706

Lu A-H, Salabas EL, Schüth F (2007) Magnetic nanoparticles: synthesis, protection, functionalization, and application. Angew Chemie Int Ed 46:1222-1244. https://doi.org/10.1002/anie.200602866

Ma P, Mumper RJ (2013) Paclitaxel nano-delivery systems: a comprehensive review. J Nanomed Nanotechnol 4:1000164. https://doi. org/10.4172/2157-7439.1000164

Mudshinge SR, Deore AB, Patil S, Bhalgat CM (2011) Nanoparticles: emerging carriers for drug delivery. Saudi Pharm J 19:129-141. https://doi.org/10.1016/j.jsps.2011.04.001

Pace A, Nisticó C, Cuppone F et al (2007) Peripheral neurotoxicity of weekly paclitaxel chemotherapy: a schedule or a dose issue? Clin Breast Cancer 7:550-554. https://doi.org/10.3816/ CBC.2007.n.010

Pankhurst QA, Connolly J, Jones SK, Dobson J (2003) Applications of magnetic nanoparticles in biomedicine. J Phys D Appl Phys 36:R167-R181. https://doi.org/10.1088/0022-3727/36/13/201

Plank C, Scherer F, Schillinger U et al (2003) Magnetofection: enhancing and targeting gene delivery with superparamagnetic nanoparticles and magnetic fields. J Liposome Res 13:29-32. https://doi. org/10.1081/LPR-120017486

Prijic S, Scancar J, Romih R et al (2010) Increased cellular uptake of biocompatible superparamagnetic iron oxide nanoparticles into malignant cells by an external magnetic field. J Membr Biol 236:167-179. https://doi.org/10.1007/s00232-010-9271-4

Raut SL, Kirthivasan B, Bommana MM et al (2010) The formulation, characterization and in vivo evaluation of a magnetic carrier for brain delivery of NIR dye. Nanotechnology 21:395102. https:// doi.org/10.1088/0957-4484/21/39/395102 
Saul JM, Annapragada A, Natarajan JV, Bellamkonda RV (2003) Controlled targeting of liposomal doxorubicin via the folate receptor in vitro. J Control Release 92:49-67

Shishodia S, Sethi G, Aggarwal BB (2005) Curcumin: getting back to the roots. Ann NY Acad Sci 1056:206-217. https://doi. org/10.1196/annals.1352.010

Slowing II, Wu C-W, Vivero-Escoto JL, Lin VS-Y (2009) Mesoporous silica nanoparticles for reducing hemolytic activity towards mammalian red blood cells. Small 5:57-62. https://doi.org/10.1002/ smll.200800926

Song H, He R, Wang K et al (2010) Anti-HIF-1 $\alpha$ antibody-conjugated pluronic triblock copolymers encapsulated with paclitaxel for tumor targeting therapy. Biomaterials 31:2302-2312. https://doi. org/10.1016/j.biomaterials.2009.11.067

Sudimack J, Lee RJ (2000) Targeted drug delivery via the folate receptor. Adv Drug Deliv Rev 41:147-162

Sui X, Chen R, Wang Z et al (2013) Autophagy and chemotherapy resistance: a promising therapeutic target for cancer treatment. Cell Death Dis 4:e838-e838. https://doi.org/10.1038/cddis .2013 .350

Sun C, Sze R, Zhang M (2006) Folic acid-PEG conjugated superparamagnetic nanoparticles for targeted cellular uptake and detection by MRI. J Biomed Mater Res Part A 78A:550-557. https://doi. org/10.1002/jbm.a.30781

Sun C, Lee J, Zhang M (2008) Magnetic nanoparticles in MR imaging and drug delivery. Adv Drug Deliv Rev 60:1252-1265. https:// doi.org/10.1016/j.addr.2008.03.018

ten Tije AJ, Verweij J, Loos WJ, Sparreboom A (2003) Pharmacological effects of formulation vehicles. Clin Pharmacokinet 42:665685. https://doi.org/10.2165/00003088-200342070-00005

Tian X, Ding F, Wu G et al (2016) Curcumin suppresses 4-hydroxytamoxifen resistance in breast cancer cells by targeting SLUG/ Hexokinase 2 pathway. Biochem Biophys Res Commun 473:147153. https://doi.org/10.1016/j.bbrc.2016.03.067

Veiseh O, Gunn JW, Zhang M (2010) Design and fabrication of magnetic nanoparticles for targeted drug delivery and imaging. Adv Drug Deliv Rev 62:284-304. https://doi.org/10.1016/j. addr.2009.11.002

Wahajuddin Arora S (2012) Superparamagnetic iron oxide nanoparticles: magnetic nanoplatforms as drug carriers. Int J Nanomedicine 7:3445. https://doi.org/10.2147/IJN.S30320
Wallace SJ, Li J, Nation RL, Boyd BJ (2012) Drug release from nanomedicines: selection of appropriate encapsulation and release methodology. Drug Deliv Transl Res 2:284-292. https://doi. org/10.1007/s13346-012-0064-4

Wang Y, Yu L, Han L et al (2007) Difunctional Pluronic copolymer micelles for paclitaxel delivery: synergistic effect of folatemediated targeting and Pluronic-mediated overcoming multidrug resistance in tumor cell lines. Int J Pharm 337:63-73. https://doi. org/10.1016/j.ijpharm.2006.12.033

Wu H, Liu G, Wang X et al (2011) Solvothermal synthesis of cobalt ferrite nanoparticles loaded on multiwalled carbon nanotubes for magnetic resonance imaging and drug delivery. Acta Biomater 7:3496-3504. https://doi.org/10.1016/j.actbio.2011.05.031

Xia W, Low PS (2010) Folate-targeted therapies for cancer. J Med Chem 53:6811-6824. https://doi.org/10.1021/jm100509v

Yallapu MM, Othman SF, Curtis ET et al (2011) Multi-functional magnetic nanoparticles for magnetic resonance imaging and cancer therapy. Biomaterials 32:1890-1905. https://doi.org/10.1016/j. biomaterials.2010.11.028

Yallapu MM, Jaggi M, Chauhan SC (2012) Curcumin nanoformulations: a future nanomedicine for cancer. Drug Discov Today 17:71-80. https://doi.org/10.1016/j.drudis.2011.09.009

Zähres M, Dehne S, Wunderlich S et al (2006) Properties of a watersoluble paclitaxel conjugate in aqueous solution and its interaction with serum albumin. Macromol Symp 231:28-46. https://doi. org/10.1002/masy.200590023

Zhang W, Shi Y, Chen Y et al (2011) Multifunctional Pluronic P123/ F127 mixed polymeric micelles loaded with paclitaxel for the treatment of multidrug resistant tumors. Biomaterials 32:28942906. https://doi.org/10.1016/j.biomaterials.2010.12.039

Zhao X, Li H, Lee RJ (2008) Targeted drug delivery via folate receptors. Expert Opin Drug Deliv 5:309-319. https://doi. org/10.1517/17425247.5.3.309

Publisher's Note Springer Nature remains neutral with regard to jurisdictional claims in published maps and institutional affiliations. 